\title{
EDUCAÇÃO AMBIENTAL APLICADA AOS RESÍDUOS SÓLIDOS URBANOS - UM ESTUDO DE CASO
}

\author{
Leila Maria Sotocorno e Silva ${ }^{1}$ \\ Yeda Ruiz Maria ${ }^{2}$ \\ Sibila Corral de Arêa Leão Honda ${ }^{3}$
}

Resumo: O atual padrão de consumismo não contribui em nada para a preservação do meio ambiente e para as necessárias mudanças de pensamento e de postura da sociedade. Nesse contexto, os resíduos sólidos urbanos, originados das diárias e diversas atividades humanas, têm sido uma das grandes problemáticas dos municípios brasileiros. Entretanto exigir o não consumo seria totalmente inviável para uma sociedade caracteristicamente capitalista. Resta assim partir em busca da construção do bom senso da sociedade com a implantação de ações de educação ambiental voltadas para a preservação do meio, atentando-se à indispensável participação da comunidade, vista que, diferentemente da utilização dos serviços de água e esgoto na qual o transporte se dá por gravidade ou por pressão, os resíduos sólidos dependem das mãos humanas, na maioria de suas fases. Assim sendo, busca-se neste artigo, apresentar a cidade de Anhumas-SP e suas ações públicas de educação ambiental, formais e informais, com relação à gestão de seus resíduos sólidos urbanos. A metodologia seguida está baseada em acompanhamento pessoal das pesquisadoras junto às ações municipais, por meio de assessoria profissional.

\footnotetext{
${ }_{1}^{1}$ Universidade do Oeste Paulista, Faculdade de Engenharia. Email: leilamaria@unoeste.br

2 Universidade do Oeste Paulista, Faculdade de Engenharia. Email: yeda@unoeste.br

${ }^{3}$ Universidade do Oeste Paulista, Faculdade de Engenharia. Email: sibila@unoeste.br
} 

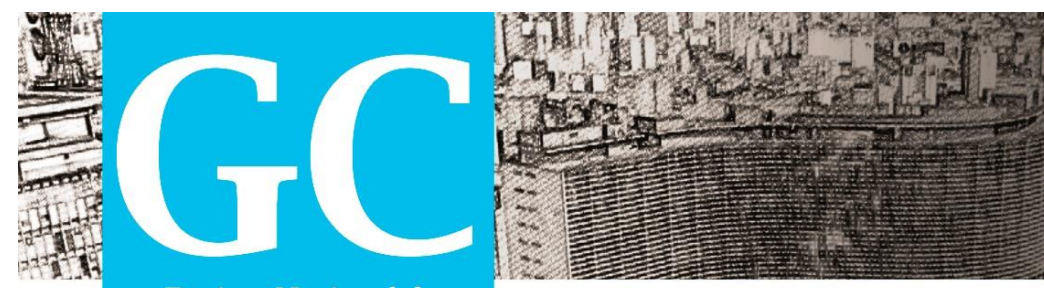

Revista Nacional de

Gerenciamento de Cidades

Palavras-chave: Educação ambiental. Resíduos sólidos urbanos. Anhumas-SP.

\section{INTRODUÇÃO}

O acelerado processo de urbanização brasileira, intensificado com a expansão das atividades industriais e de serviços, tem resultado em contínua atração de pessoas para as cidades em busca de melhores condições de vida. Esse cenário histórico descreve o início das drásticas mudanças na natureza, causando diversos problemas ambientais.

Nesse sentido, Loureiro (2003), em sua ampla e crítica visão, enfatiza que tal cenário estimula a coisificar tudo e todos, com banalização da vida, individualismo exacerbado, e separação na compreensão do humano e da natureza, que é, em tese, antagônico a projetos ambientalistas. $O$ atual padrão de consumismo não contribui em nada para a preservação do meio ambiente e para as necessárias mudanças de pensamento e de postura da sociedade.

Porém exigir o não consumo seria totalmente inviável para uma sociedade caracteristicamente capitalista. Resta, assim, partir em busca da construção do bom senso da sociedade com a implantação de ações de educação ambiental voltada para a preservação do meio.

Enfatiza Rohde (2012) que é preciso educar a população no sentido de mostrar que não basta apenas limpar os rios e reflorestar os campos para vivermos num planeta sustentável, mas sim tratar dos problemas sociais, os seres humanos. Nesse contexto, os resíduos sólidos urbanos, originados das diárias e diversas atividades humanas, têm sido uma das grandes problemáticas dos municípios brasileiros.

Para Oliveira (2002) e Bucci $(2002,2006)$, a solução desses problemas que envolvem a geração, a coleta e disposição final dos resíduos sólidos urbanos dependem da criação de políticas públicas específicas, aqui compreendidas como programas de ação governamental que visam a coordenar os meios à disposição do Estado e as atividades privadas para a realização de objetivos socialmente relevantes e politicamente determinados. 

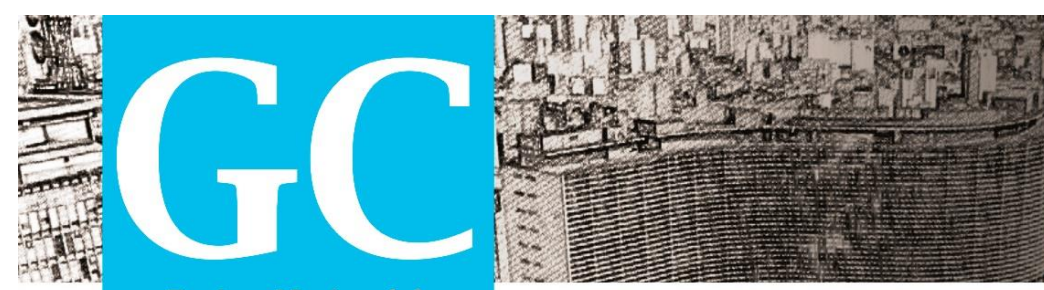

Revista Nacional de

Gerenciamento de Cidades

E a educação ambiental deve ser vista como um guia para as transformações da sociedade em direção a novos paradigmas de justiça social e qualidade ambiental, sendo uma mola propulsora para a solucionar problemas ambientais, e especificamente propõe uma educação que trata da participação da sociedade nas questões ambientais em discussões e decisões sobre o futuro do planeta. E para que o cidadão consiga colaborar com alternativas ambientalistas, é necessário que este consiga estabelecer um diálogo entre as gerações, culturas e hábitos diferentes (GUIMARÃES, 2000; MANO, 2005; REIGOTA, 2007).

$\mathrm{E}$, relativo à educação ambiental voltada à coleta seletiva e gestão de resíduos sólidos e à sua prática política, é indispensável a participação da comunidade, visto que, diferentemente da utilização dos serviços de água e esgoto na qual o transporte se dá por gravidade ou por pressão, os resíduos sólidos dependem da vontade da sociedade na maioria de suas fases.

A Política Nacional de Resíduos Sólidos - PNRS (Lei federal no 12.305/2010 e Decreto 7.404/2010) é instrumento fundamental de responsabilidade pública nas temáticas da educação ambiental e resíduos sólidos urbanos. Exige conhecimentos, posturas, aprendizados e práticas para que as soluções se estabeleçam e desenvolvam mecanismos que promovam a preservação ambiental, a inclusão social, 0 desenvolvimento sustentado e a colaboração comunitária (IPEA, 2012).

A educação ambiental é a ferramenta com capacidade para construir esses processos e está expressa na Política Nacional de Educação Ambiental - PNEA (Lei Federal nำ 9.795/1999) e regulamentada pelo Decreto 4.281/2002. A definição adotada de educação ambiental considera:

[...] os processos por meio dos quais o indivíduo e a coletividade constroem valores sociais, conhecimentos, habilidades, atitudes e competências voltadas para a conservação do meio ambiente, bem de uso comum do povo, essencial à sadia qualidade de vida e sua sustentabilidade (PNEA, capítulo I, art. 1ํ)

Dessa forma, é entendido que a educação ambiental quando voltada aos resíduos sólidos urbanos, deve envolver muitas e distintas formas de relacionamentos, ações e comunicação com as comunidades, criando uma dinâmica e tipologia própria: 

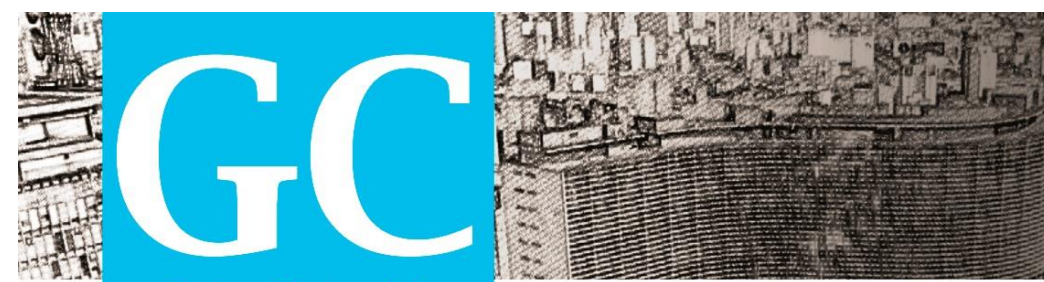

Revista Nacional de

Gerenciamento de Cidades

- Informações objetivas e orientações para a participação de determinada população ou comunidade em programas e ações.

- Mobilização/sensibilização das comunidades envolvidas diretamente.

- $\quad$ Campanhas e ações pontuais de mobilização com influencia na população que se pretende sensibilizar.

- Informações, sensibilizações e mobilizações desenvolvidas em espaços escolares.

Entender a educação ambiental com uma política pública torna-se realmente indispensável diante de uma população extremamente necessitada de mudanças de paradigmas. Com a implementação da Política Nacional de Resíduos Sólidos e do Plano Nacional de Resíduos Sólidos, assim como dos outros decorrentes, a necessidade deste tipo de informação será maior. Haja vista que e a população será trabalhada para descartar seus resíduos, ou pelo menos parte deles, de forma diferente do que está habituada, nos Planos Municipais de Resíduos e na gestão compartilhada prevista (IPEA, 2012).

E Sorrentino (1995) afirma que a educação ambiental como política pública é tida como base orientadora para as mudanças de comportamento ou visando a resultados em prol da comunidade.

De modo formal ou não formal, o Poder Publico deve tomar ciência das reais necessidades do ambiente que governa, a fim de criar as diretrizes viáveis a serem implantadas em prol das presentes e futuras gerações, tendo em vista que é indiscutível o fato de que a educação ambiental é uma política necessária e indispensável como instrumento sensibilizador da população envolvida.

Nesse contexto, é importante identificar situações e políticas públicas urbanas que têm efetivamente agido no âmbito de educação ambiental e de adequada coleta seletiva com participação da comunidade. Assim sendo, busca-se neste artigo, apresentar a cidade de Anhumas, no oeste do Estado de São Paulo, e suas ações públicas de educação ambiental. 

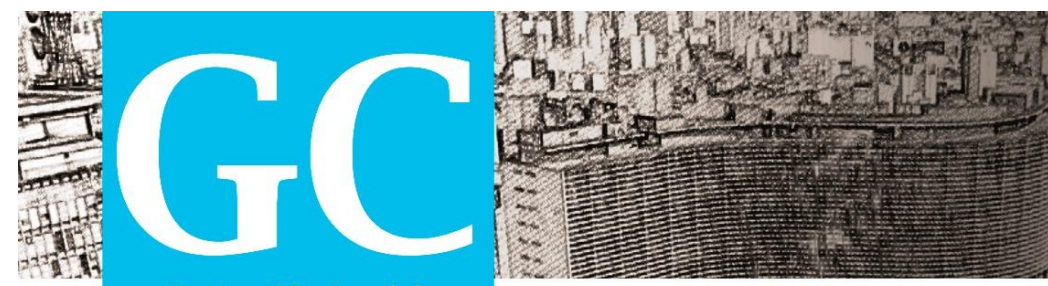

Revista Nacional de

Gerenciamento de Cidades

\section{ANHUMAS-SP - UM DIFERENCIAL NO OESTE PAULISTA}

Segundo o Relatório de Qualidade Ambiental do Estado de São Paulo (2007), o município de Anhumas está situado na $10^{\underline{a}}$ Região Administrativa do Estado de São Paulo, presente entre os municípios da região de Presidente Prudente conhecida por Pontal do Paranapanema. Possui $320,93 \mathrm{~km}^{2}$ de extensão territorial e população estimada em 3.738 habitantes (IBGE, 2011).

Preocupado com a adoção de um adequado sistema de gerenciamento dos resíduos sólidos urbanos, e almejando o cumprimento da Lei Federal 12.305/2010 referente à Política Nacional dos Resíduos Sólidos, bem como da Lei Estadual 12.300/2006 que institui a Politica Estadual de Resíduos Sólidos, o município de Anhumas tem desenvolvido desde meados do ano de 2009 ações de educação ambiental referentes à temática resíduos sólidos.

De acordo com a Política Nacional dos Resíduos Sólidos, surge o conceito de responsabilidade compartilhada pelo ciclo de vida dos produtos, e, baseado nesse critério pré-estabelecido, parte-se do pressuposto de que cabe não só aos fabricantes e distribuidores dos diferentes produtos, mas também aos consumidores em geral, a obrigatoriedade em zelar pelo meio ambiente por meio da redução dos resíduos sólidos e rejeitos gerados.

Diante disso, nota-se a importância da promoção de ações de educação ambiental em nível municipal capazes de promover o esclarecimento à população sobre as principais dúvidas relativas ao manejo adequado dos resíduos sólidos urbanos e também ao papel que lhes compete dentro do sistema de gerenciamento dos mesmos.

A sensibilização da população municipal tem se dado em âmbito formal e informal, como se segue.

\subsection{Educação ambiental em âmbito formal - análise de caso}

Sabe-se que para que haja a sensibilização dos alunos e consequente tomada de 

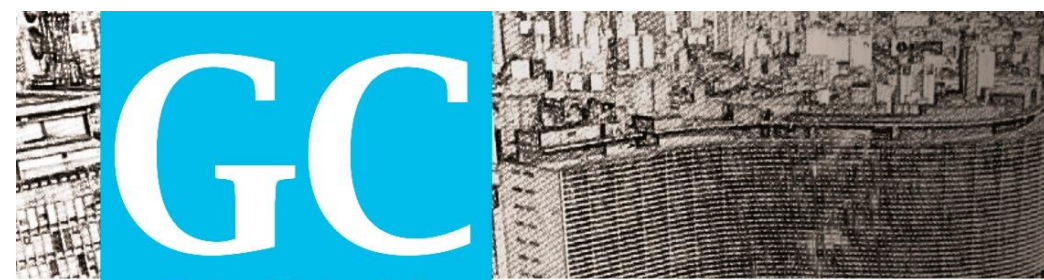

Revista Nacional de

Gerenciamento de Cidades

atitude por parte deles, é fundamental que os responsáveis pelo ensino, sobretudo os professores, estejam familiarizados com o tema e sejam eles os primeiros a serem sensibilizados com as questões ambientais.

Sendo assim, com o objetivo de promover a capacitação de professores e também agentes de saúde municipais, foram realizados no município de Anhumas curso e palestras, totalizando a carga horária de 36 horas, no período compreendido entre 03 de setembro a 10 de outubro de 2009.

O curso e as palestras focaram em noções básicas sobre a geração, a segregação, o acondicionamento, o tratamento e a destinação final de resíduos sólidos. $O$ intuito principal do curso era capacitar tecnicamente professores e agentes de saúde tornandoos agentes ambientais comprometidos com a divulgação do Programa Coleta Seletiva Solidária Municipal, que na época estava em fase inicial de planejamento.

Pode-se notar ao longo do curso o despertar do interesse pelas questões referentes ao manejo dos resíduos sólidos, haja vista a assiduidade dos alunos no curso e sobretudo o envolvimento dos mesmos.

Em seguida, partiu-se para a educação em âmbito escolar ao longo do ano de 2010, com o intuito de despertar o interesse dos alunos pertencentes ao ensino fundamental, em especial, crianças de 6 a 10 anos, em relação à temática, e principalmente às questões relativas à Coleta Seletiva. Várias palestras foram realizadas, assim como um concurso para a escolha do Mascote da Coleta Seletiva Municipal (Figura $1)$. 


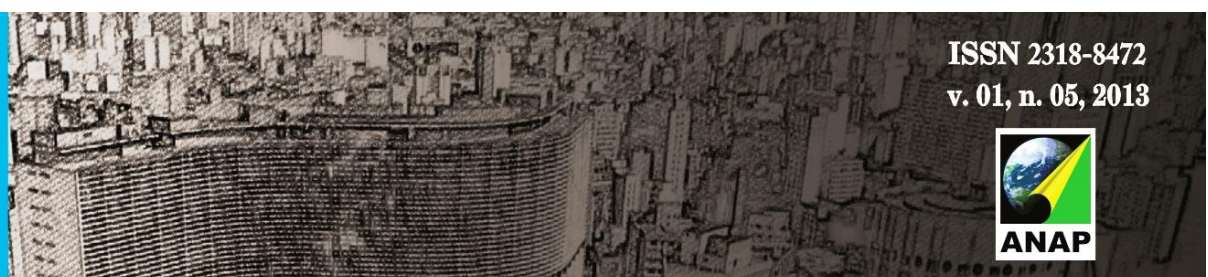

Revista Nacional de

Gerenciamento de Cidades

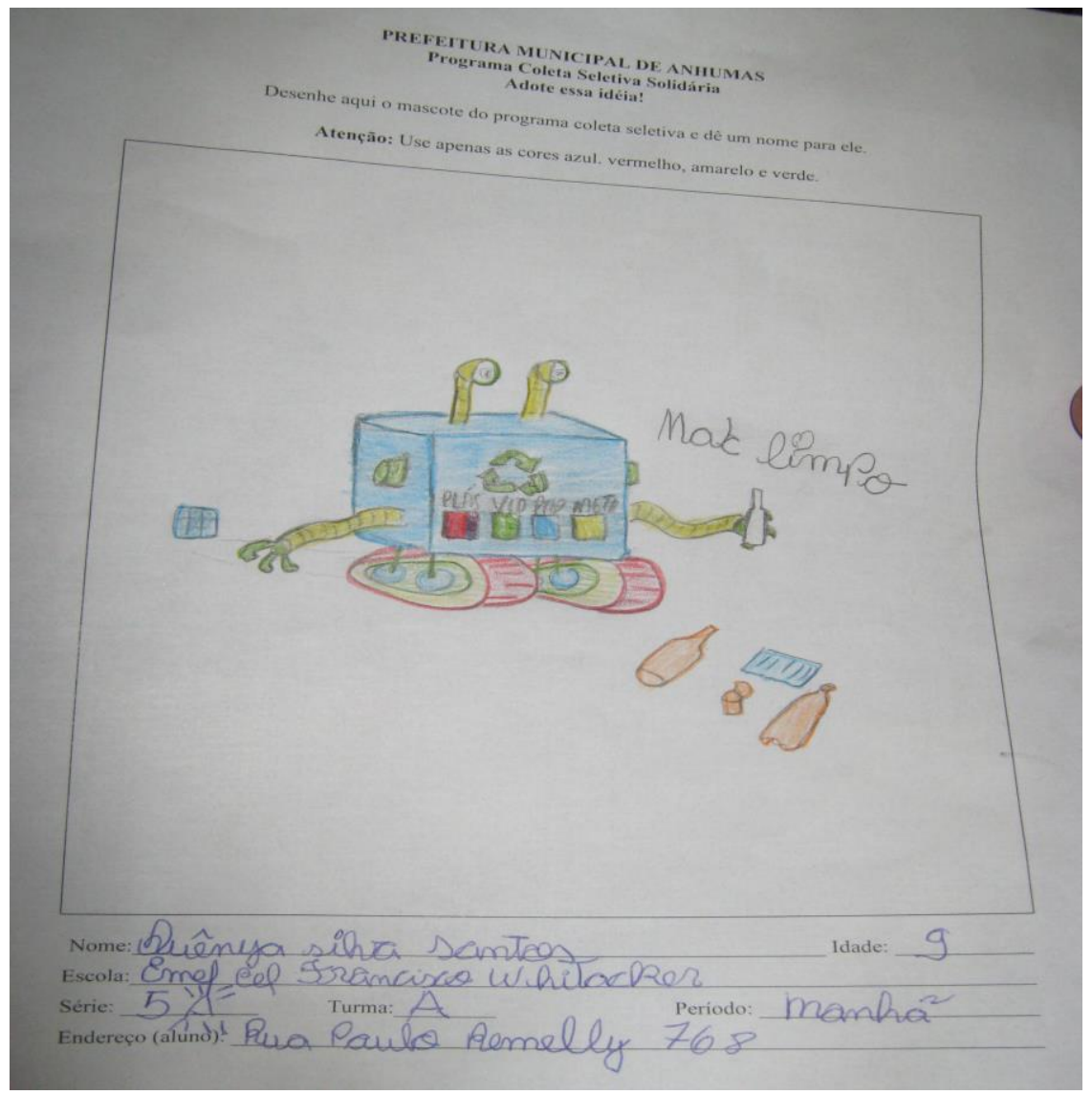

FIGURA 1 - Desenho vencedor do concurso para a escolha do mascote da Coleta Seletiva.

Fonte: Assessoria de Agricultura e Meio Ambiente de Anhumas (2010).

Ao longo dos anos de 2011 e 2012, foram desenvolvidas ações de educação ambiental envolvendo crianças e jovens da rede municipal e estadual de ensino. As ações se deram por meio da realização de palestras e atividades culturais.

Com a implantação da Coleta Seletiva em março de 2013, as ações de educação ambiental foram intensificadas, por meio da distribuição de cartilhas educativas aos alunos do segundo ao quinto anos do ensino fundamental, com o intuito de promover a educação sobre a questão dos resíduos sólidos urbanos gerados em seu município, e também estimulá-los a participar do Programa de Coleta Seletiva Solidária, haja vista a importância das crianças em um programa como este. 

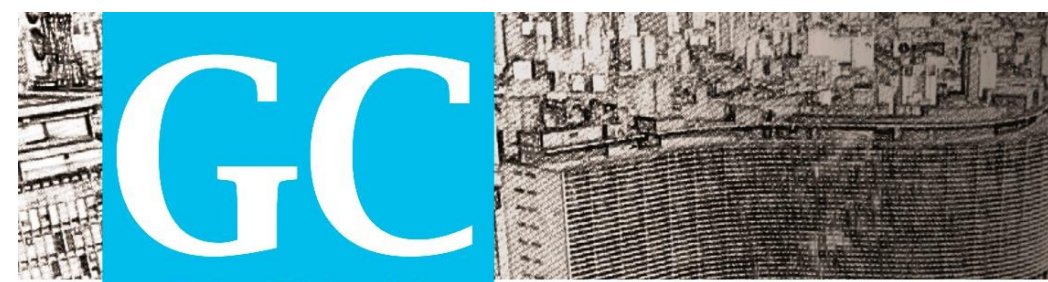

Revista Nacional de

Gerenciamento de Cidades

\subsection{Educação Ambiental em Âmbito Informal}

A educação ambiental voltada à gestão dos resíduos sólidos urbanos foi estendida à população em geral, por meio da distribuição de folders explicativos sobre o Programa Coleta Seletiva Solidária e também através de materiais de divulgação, tais como faixas, cartazes colocados em pontos estratégicos da malha urbana.

Mutirões para recolhimento de resíduos eletroeletrônicos bem como campanhas para recolhimento de óleo de cozinha têm sido realizados no município de maneira contínua desde o ano de 2009.

Outra ação realizada, foi o contato pessoal com os comerciantes e comerciários da cidade, tratando de informações sobre o serviço e operacionalização da coleta seletiva, com indagações sobre tipologia dos materiais entregues e seus volumes, e estímulo e/ou empecilhos para adesão ao Programa de Coleta Seletiva.

Também tem havido engajamento das igrejas locais, com divulgação e estímulo aos fiéis; como anúncio em carros de som.

\section{PANORAMA ATUAL}

A partir da implantação do Programa de Coleta Seletiva em Anhumas, por meio de pesagens, pode-se verificar grande engajamento da população. Ao longo do primeiro mês do programa, ocorreu adesão de aproximadamente $40 \%$ da população urbana.

$E$, com as ações pontuais que são mantidas pode-se notar, visualmente, incremento da participação da população. Outras características que chamam a atenção, referem-se à maior adesão das famílias que possuem crianças em idade escolar, e menor participação das famílias de classes de renda menor.

Entretanto, nota-se, no município, que há uma intensa engajamento da população em todas as ações de educação ambiental desenvolvidas, fazendo do município um diferencial na região do Oeste Paulista, onde a questão dos resíduos sólidos tem figurado como um dos principais desafios da atualidade. 

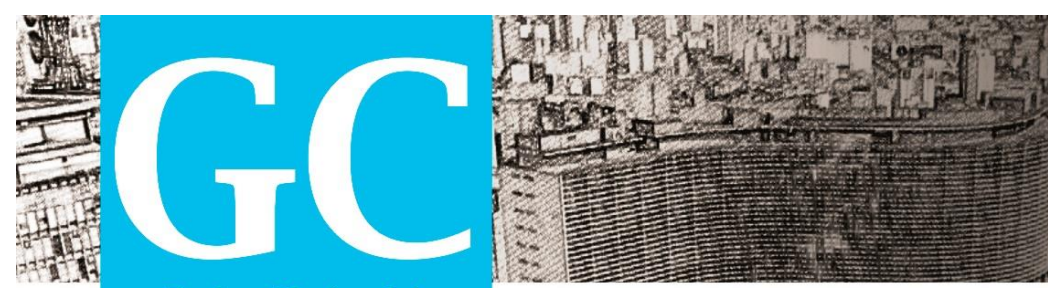

Revista Nacional de

Gerenciamento de Cidades

\section{CONCLUSÃO}

A busca pela adoção de um adequado e eficiente sistema de gerenciamento de resíduos sólidos urbanos constitui-se em um dos principais desafios enfrentados pela grande maioria dos municípios brasileiros.

Diferentemente dos demais serviços prestados à comunidade, o gerenciamento dos resíduos sólidos exige efetiva participação da comunidade, em todas as suas etapas. Sendo assim, nota-se a relevância da prática de ações de educação ambiental voltadas a essa temática, quer seja em âmbito formal ou informal.

Dentro deste contexto, o município de Anhumas tem se diferenciado dos demais municípios da região do oeste paulista em virtude do engajamento da população nas ações de educação ambiental realizadas e, sobretudo nos resultados positivos alcançados na questão do gerenciamento dos resíduos sólidos urbanos, principalmente em relação ao Programa de Coleta Seletiva Municipal recentemente implantado.

\section{REFERÊNCIAS}

BUCCI, M.P. Direito administrativo e políticas públicas. São Paulo: Saraiva, 2002.

BUCCI, M.P.D. (org.) Políticas públicas: reflexões sobre o conceito jurídico. São Paulo: Saraiva, 2006.

GUIMARÃES, M. A dimensão ambiental na educação. In: Colégio Magistério: Formação e trabalho pedagógico. Campinas, 2000.

IPEA - Instituto de pesquisa econômica aplicada. Diagnóstico de Educação Ambiental em Resíduos Sólidos - Relatório de Pesquisa. Brasília: Ipea, 2012.

LOUREIRO, C. F. B. Premissas teóricas para uma educação ambiental transformadora. In: Revista Eletrônica Ambiente e Educação. Rio Grande. V 8. 17 p. 37-54. 2003.

MANO, E.B. Meio ambiente, poluição e reciclagem. São Paulo: Edgar Blucher, 2005.

OLIVEIRA, L. A Percepção do Meio Ambiente em Geografia. In: Revista OLAM. Ciencia e Tecnologia. Rio Claro, 2002.

REIGOTA, M. Meio Ambiente e representação social. 7.ed. São Paulo: Cortez, 2007. 


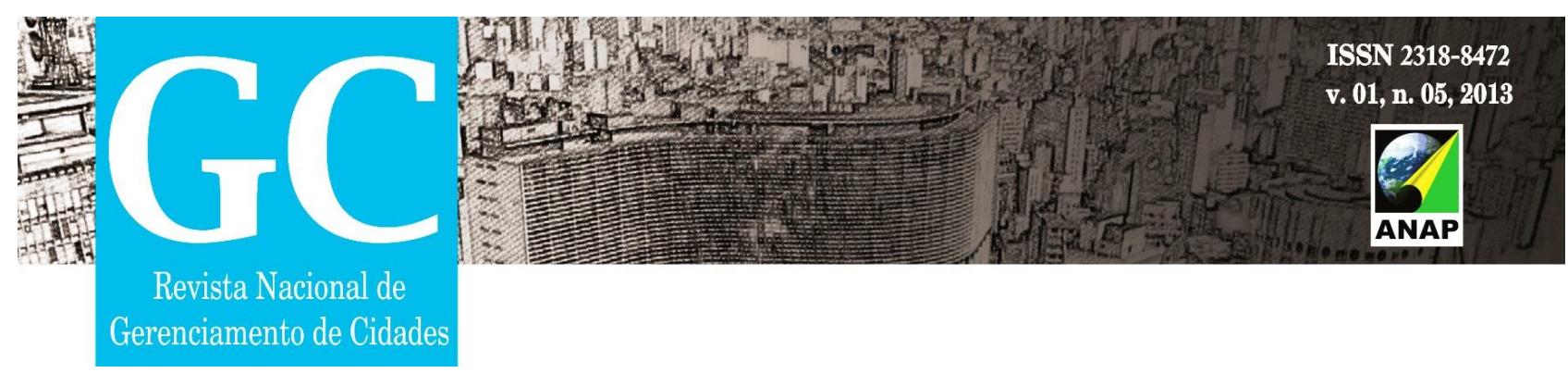

ROHDE, M.D.S; SILVA, F.S.; FRASSON, V.R.; RIBEIRO, A.A. Análise do problema dos resíduos sólidos de origem doméstica no meio urbano a partir do uso de mapas mentais por alunos do ensino fundamental no município de rosário do sul-rs. In: Revista Geo Norte, edição especial, v. 3, p. 24-32, 2012.

SORRENTINO, M. Educação Ambiental e Universidade: Um estudo de caso. São Paulo: Faculdade de Educação - USP, 1995. (Tese de Doutorado) 